\title{
Behavior of the Switching Effect in P-Type TIInS 2 Ternary Chalcogenide Semiconductor
}

\author{
A. T. Nagat, F. S. Bahabri, M. M. Mobark, H. T. Shaban, \\ A. A. Al Ghamdi and S. R. Alharbi \\ Physics Department, Girls college of Education in Jeddah, KSA \\ 1- Physics Department, Faculty of sciences, South Valley University, \\ Qena, Egypt \\ 2-Physics Department, Faculty of Sciences, King Abdulaziz University, \\ $K S A$
}

\begin{abstract}
Investigation of the switching phenomenon in single crystal $\mathrm{TlInS}_{2}$ revealed that it is typical for a memory switch. The switching process takes place with both polarities on the crystal and have symmetrical shapes. Current-voltage characteristics (CVC) of symmetrical $\mathrm{Ag} / \mathrm{p}-\mathrm{Tl} \mathrm{InS}_{2} / \mathrm{Ag}$ structures exhibit two distinct regions, high resistance OFF state and low-resistance ON state having negative differential resistance (NDR). $\mathrm{TlInS}_{2}$ is a ternary semiconductor exhibiting S-type i-v characteristics. The results strongly indicate that the phenomenon in our sample is very sensitive to temperature, light intensity and sample thickness. The switching parameters were checked under the influence of different factors of the ambient condition.
\end{abstract}

\section{Introduction}

For the last few years there have been considerable interest in the investigation of physical properties of layered ternary crystal with chemical formula $\mathrm{TlBX}_{2}$, where $\mathrm{B}=\mathrm{Ga}$ or $\mathrm{In}$ and $\mathrm{X}=\mathrm{S}$ or $\mathrm{Se}^{[1]}$. The lattice of $\mathrm{TlBX}_{2}$ type crystals consist of alternating two dimensional layers arranged parallel to the (001) plane ${ }^{[2]}$. Each successive layer is turned through a right angle relative to the preceding one. $\mathrm{TlInS}_{2}$, which is a member of this class of crystals, is a semiconductor with an indirect 
band gap of about $2.28 \mathrm{eV}$ at room temperature ${ }^{[3]}$. Some of the physical properties of $\mathrm{TlInS}_{2}$, have been investigated by many authors ${ }^{[4-9]}$. The aim of this work is to study the switching phenomenon in Thallium Indium disulphide single crystal in wide range of temperatures as well as light intensity and sample thickness. To the best of our knowledge, switching investigation in this compound has not been reported before. The absence of data on the characteristics of switching about the compound $\mathrm{Tl} \mathrm{InS}_{2}$ makes it difficult to estimate potential application of this material.

\section{Instrumentation}

The samples used in this study were $\mathrm{TlInS}_{2}$ crystal (melting point $\left.770^{\circ} \mathrm{c}\right)^{[10]}$ grown in an evacuated quartz ampoule by using the modified Bridgman method in a special design ${ }^{[1]}$. X-ray diffraction studies XRD and differential thermal analyses DTA, were performed to assure the presence of the crystalline phase in the prepared ingot. All samples used in this work were freshly cleaved from the same grown ingots, and no further polishing treatments were required, because of the natural mirrorlike cleavage faces. They were rectangularly shaped with parallel faces. A dc current source was connected to the ends of the rectangular-shaped samples so that the current flow is perpendicular to the crystallographic $\mathrm{c}$-axis. The $i-\mathrm{v}$ characteristics were measured, using a simple circuit containing a dc power supply, current meter, and series load resistance. The applied voltage can be increased steadily up to the point where the crystal switched, after which the series resistance limited the applied voltage for preventing crystal destruction. Current-voltage characteristics were measured at different ambient temperatures in the range of 163 to $303 \mathrm{~K}$. At room temperature the effect of illumination intensity in the range of 300 to 1500 Lux was investigated. To study the effect of sample thickness, the thickness was altered between 0.34 and $0.18 \mathrm{~cm}$. A point contact holder was used in the measurement of the switching phenomena. Measurements below room temperature were done using liquid nitrogen. The temperature was measured using a cu-constantan thermocouple. White light was focused on the sample surface for studying the effect of light intensity on the switching behavior. The intensity of the radiation was measured with a luxmeter. Samples with different thick-ness were used to investigate the influence of the sample thickness on the switching characteristics. Details of the experimental procedures and apparatus were published earlier ${ }^{[12]}$. 


\section{Results and Discussion}

The general behavior of the current-voltage characteristics for virgin sample of $\mathrm{TlInS}_{2}$ single crystals has a characteristic shape as given schematically in Fig. 1. It is symmetric with respect to the polarity. Thallium Indium disulphide is a ternary semiconductor exhibiting S-type $\mathrm{i}-\mathrm{v}$ characteristics, similar to the curves shown by many authors ${ }^{[13-18]}$. As is seen from $i$-v behavior, there are two distinct regions; one is the OFFstate and the other is the NDR regions. The temperature dependence of the $\mathrm{i}-\mathrm{v}$ characteristics for $\mathrm{TlInS}_{2}$ compound is shown in Fig. 2. As is evident from the experimental curves as well as predicted by the electrothermal model ${ }^{[19-21]}$, the ambient temperature greatly influences both the form of the $\mathrm{i}-\mathrm{v}$ curves and the threshold voltage $\mathrm{v}_{\mathrm{th}}$. The effect of the ambient temperature on the switching parameters $v_{\text {th }}$ and $i_{\text {th }}$ is illustrated in Fig. 3. It is clear from the figures that as the temperature increases the threshold voltage decreases and the threshold current increases. This indicates that an electrothermal mechanism is involved in the switching process. As observed from the curves of Fig. 1 and 2 some common features are shown such as the following:

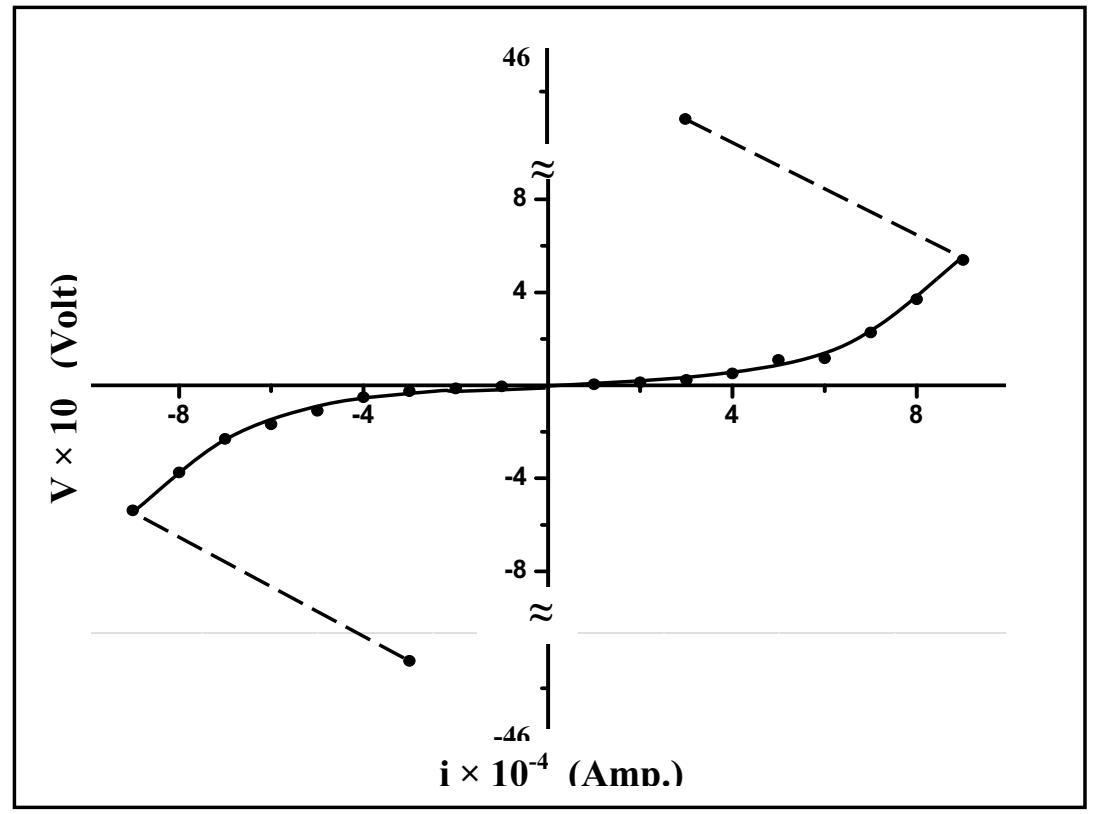

Fig.1 Current-voltage characteristics at room temperature for $\mathrm{TIInS}_{2}$ single crystal. 


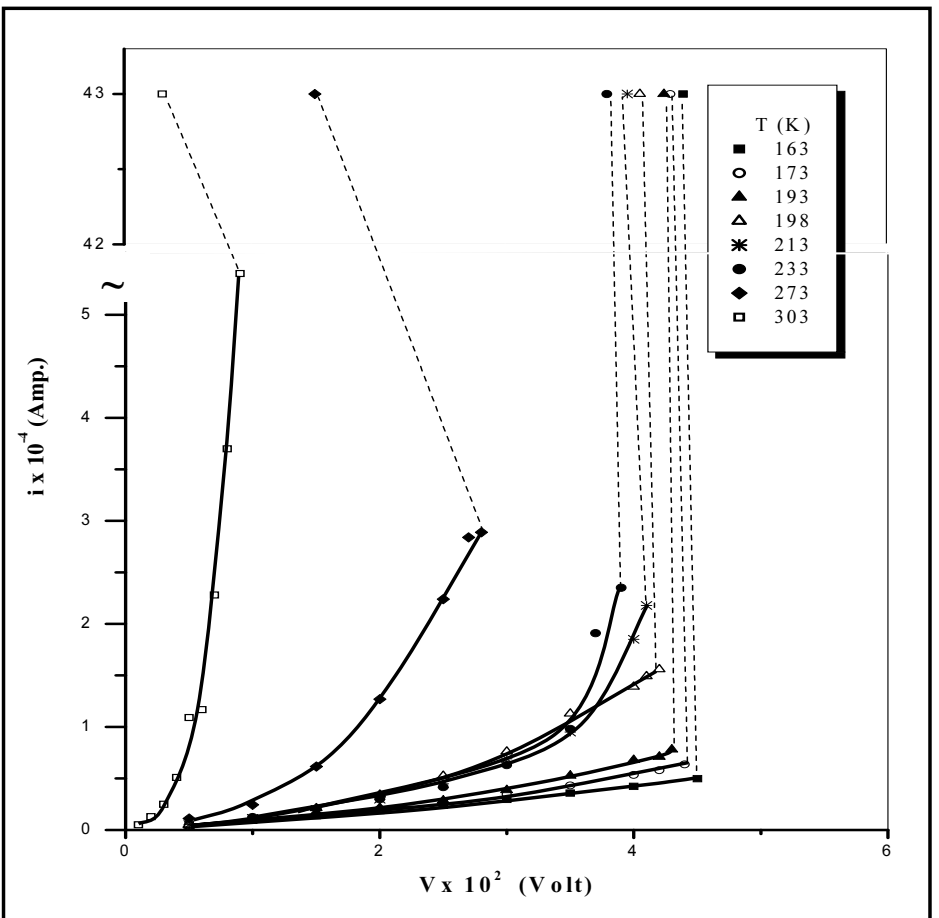

Fig. 2. Current-voltage characteristics at different values of temperature for $\mathrm{TIInS}_{2}$ single crystal.

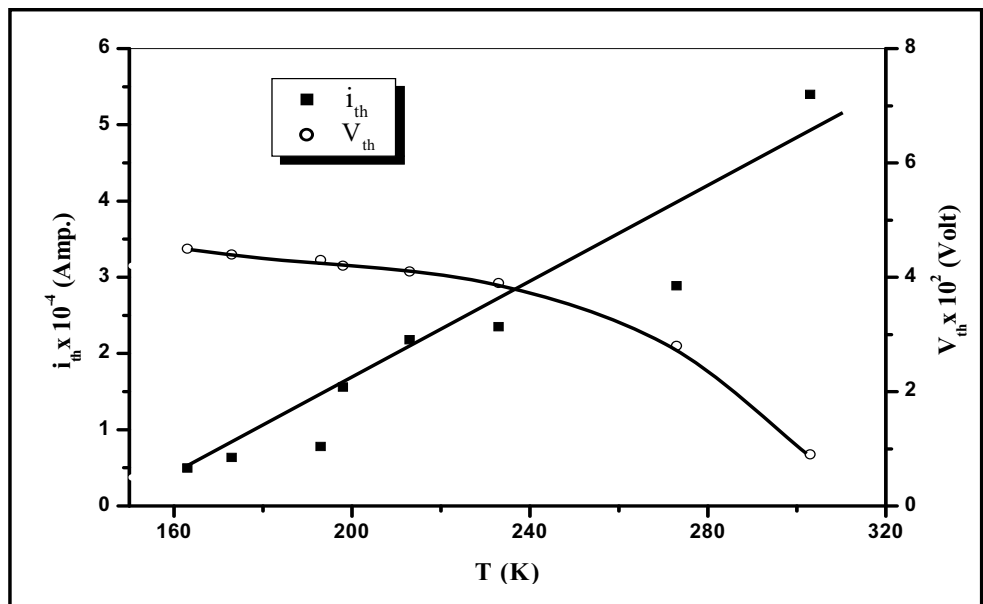

Fig.3. Ambient temperature effect on threshold current and voltage for $\mathrm{TIInS}_{2}$ single crystal. 
1- S-shaped curves in the higher current density regions with a rather pronounce negative-differential-resistance region, which sets in after a critical current value $\left(i_{\text {th }}\right)$ threshold current.

2- The NDR portion of the curves are more pronounced at lower ambient temperature.

3- The transition from the low to the high conductivity state of the curves is almost abrupt at lower temperature.

4- The threshold voltage $\mathrm{v}_{\text {th }}$, after which the NDR region sets in, becomes higher with decreasing temperature.

5- The sample remains in the ON state if the current reduced to zero, i.e. under the zero bias condition, the sample stays in the ON state. This indicates that the memory state persists if the current is decreased slowly to its zero value. However, if the current was forced to decay suddenly, the specimen returns to the high resistance state.

The dependence of $v_{t h}^{1 / 2}$ on $T$ is plotted in Fig. 4 on the basis of the thermal-field. This figure obeys the following relation ${ }^{(15)}$

$$
\mathrm{v}_{\mathrm{th}}^{1 / 2} \approx\left[\frac{\pi \varepsilon_{o} \varepsilon_{\infty} d}{e}\right]^{1 / 2}(\varphi-c T)
$$

in the temperature range $163-303 \mathrm{~K}$, where $\varepsilon_{o}$ is the permittivity of vacuum, $\varepsilon_{\infty}$ is the electron component of permittivity, $d$ is the distance between the electrodes, $c$ is a constant, $e$ is the electron charge, $\varphi$ is the depth of the potential well, $\mathrm{T}$ is the absolute temperature. This shows that the switching in $\mathrm{Ag}-\mathrm{TlInS} \mathrm{I}_{2}-\mathrm{Ag}$ structures from high to a low resistivity state occurs under the simultaneous action of an electric field and temperature ${ }^{[22]}$. This must be supported by the dependence of threshold field on the thickness of the active region. The power necessary to change the material from the high-resistance state to the low-resistance state is called threshold power $\left(\mathrm{P}_{\text {th }}\right)$. Calculation showed that the magnitude of $\mathrm{P}_{\text {th }}$ increases with temperature up to a certain value of temperature, then $\mathrm{P}_{\text {th }}$ smoothly decreases. The decrease of $\mathrm{P}_{\text {th }}$ with temperature is not a linear but has an exponential relation as shown in 
Fig. 5. The resistance ratio $\mathrm{R}_{\mathrm{OFF}} / \mathrm{R}_{\mathrm{ON}}$ is a temperature dependent, where it decreases with temperature up to $233 \mathrm{~K}$ after which $\mathrm{R}_{\mathrm{OFF}} / \mathrm{R}_{\mathrm{ON}}$ increases slowly with temperature. The resistance ratio $\mathrm{R}_{\mathrm{OFF}} / \mathrm{R}_{\mathrm{ON}}$ for our sample at room temperature is of the order of 23.889. The high- and low resistivity states of $\mathrm{Ag}-\mathrm{T} 1 \mathrm{InS}_{2}-\mathrm{Ag}$ structures are sensitive to the light intensity. The current-voltage characteristics at different values of the light intensity at room temperature are plotted in Fig. 6. As is evident from the curves, the form of the $\mathrm{VAC}$ and the magnitude of photocurrent depends strongly on the intensity of the incident light. With decrease in intensity of the incident light, the VAC as a whole is shifted towards higher potentials. This means that in case of weak illumination the threshold voltage is larger and the current threshold value is smaller than the value obtained in case of intense light. In this case the Lux-ampere characteristic of $\mathrm{TlInS}_{2}$ crystals obeys a linear relation. Fig. 7 illustrates the dependence of $\mathrm{v}_{\text {th }}$ and $\mathrm{i}_{\text {th }}$ on light intensity I. As it is seen threshold voltage decreases exponentially with increasing light intensity, whereas the threshold current increases linearly with light illumination.

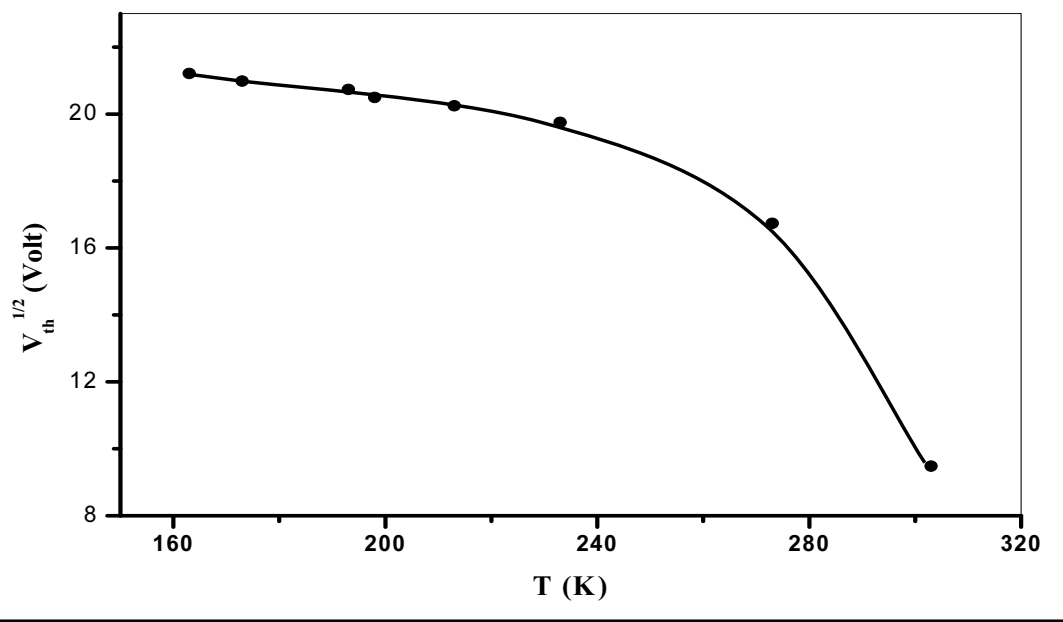

Fig. 4. Temperature dependence of $\mathrm{V}_{\text {th }}^{1 / 2}$ for $\mathrm{TIInS}_{2}$ single crystal. 


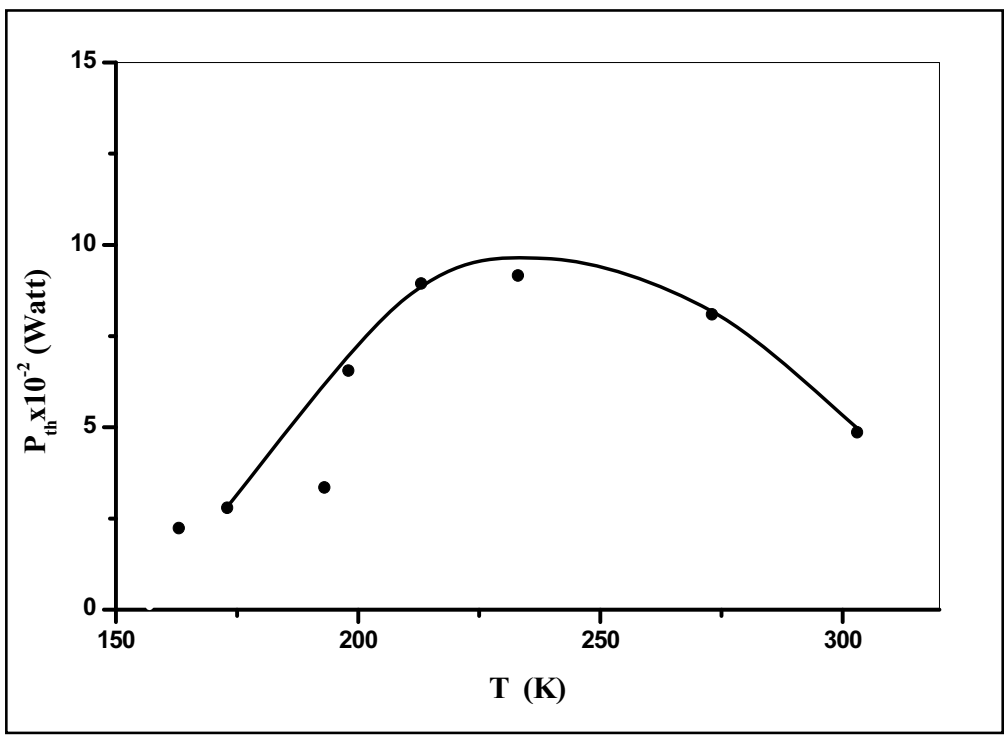

Fig. 5, Temperature dependence of $P_{t h}$ for TIInS $_{2}$ single crystal.

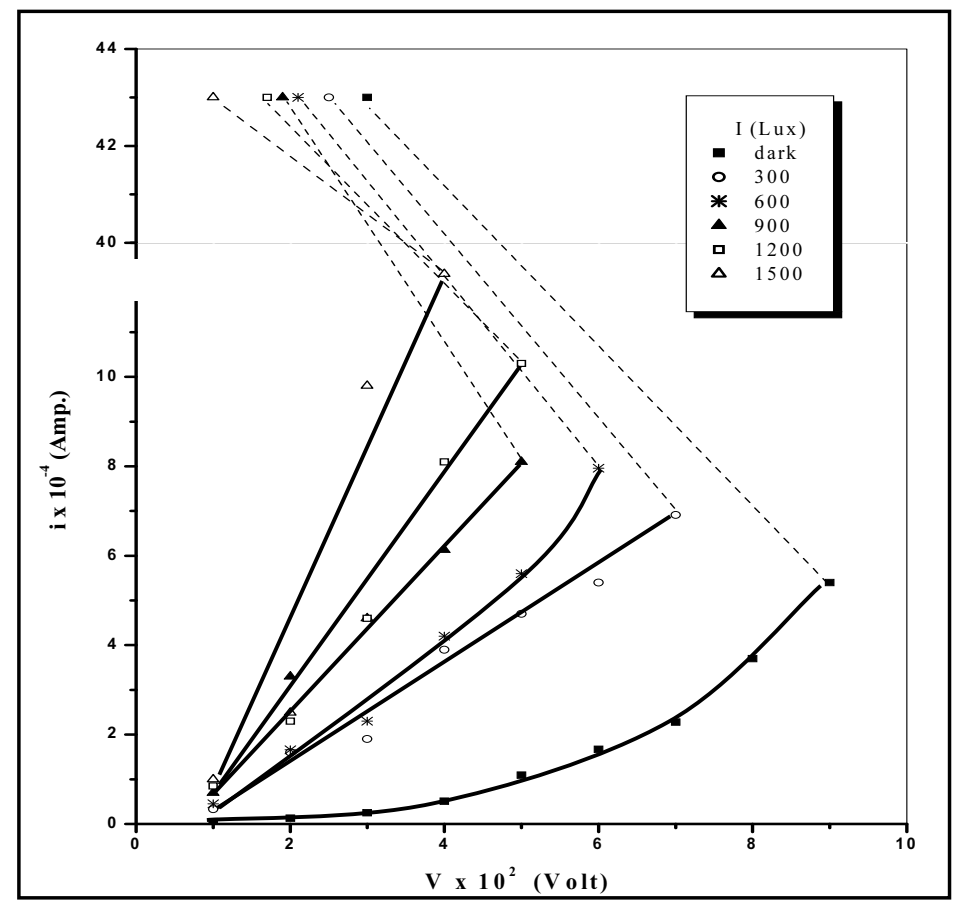

Fig. 6. Influence of light intensity on the i-v characteristics of $\mathrm{TIInS}_{2}$ single crystal. 


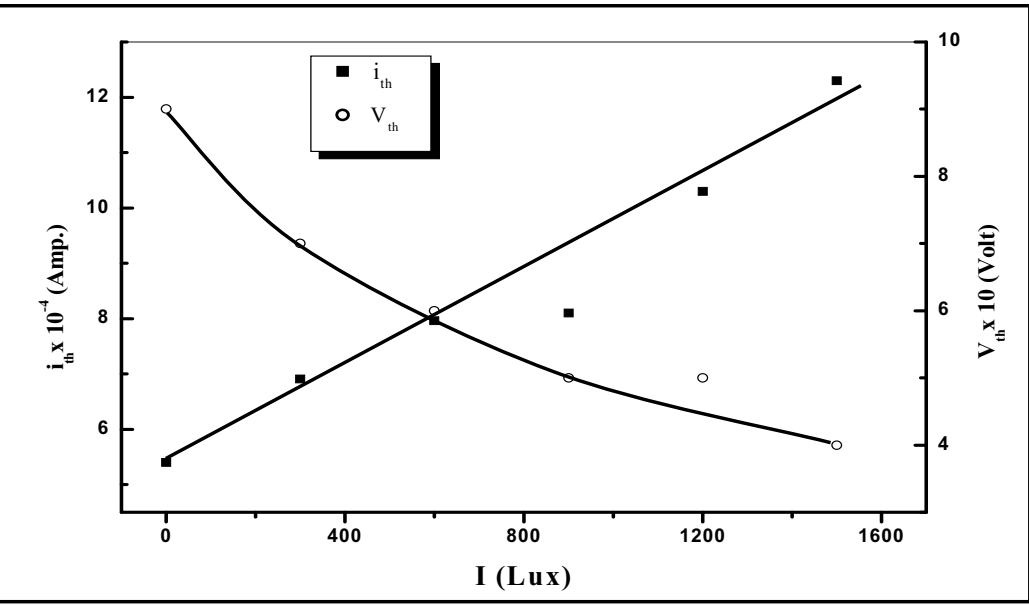

Fig. 7. Dependence of $i_{\text {th }}$ and $v_{\text {th }}$ on light intensity for TIInS$_{2}$ single crystal.

The main contribution comes from photocarrier generation through excitation states. The threshold power decreases gradually with light intensity I as shown in Fig. 8. An inverse proportionality is observed between $\mathrm{P}_{\text {th }}$ and $\mathrm{I}$. This indicates that, as the intensity increases, the rate of generation is much higher than the recombination processes, which take place besides generation. This leads to a small switching power required as the intensity of illumination increases. The dependences of the ratio $\mathrm{R}_{\mathrm{OFF}} / \mathrm{R}_{\mathrm{ON}}$ on illumination intensity is expected. The ON-state resistance at room temperature as calculated is 17.42 and it decreases as the light intensity increases reaching 13.98 at 1800 Lux. It is important to observe the influence of the sample thickness on the switching characteristics. Room temperature $\mathrm{i}-\mathrm{v}$ characteristics for the investigated compound were studied for samples of thicknesses $(0.34-0.18 \mathrm{~cm})$. Figure 9 represents the dependence of the switching behavior on the thickness of the $\mathrm{TlInS} \mathrm{I}_{2}$ specimen. The figure indicates that the threshold potential changes with the specimen thickness, and the width of the dashed lines, which represent the variation from the OFF- to ON state decreases with increasing of thickness. This result indicates that the switching can be easily controlled with the sample thickness. The holding current and voltage are also affected with the active thickness of the specimen. A variation of the threshold voltage and current with the thickness of the sample can be observed from Fig. 10, which represent a graph of $v_{\text {th }}$ and $i_{\text {th }}$ against $(d)$. It is clear from the curves that the threshold voltage decreases linearly and rapidly with increasing the sample thickness. 


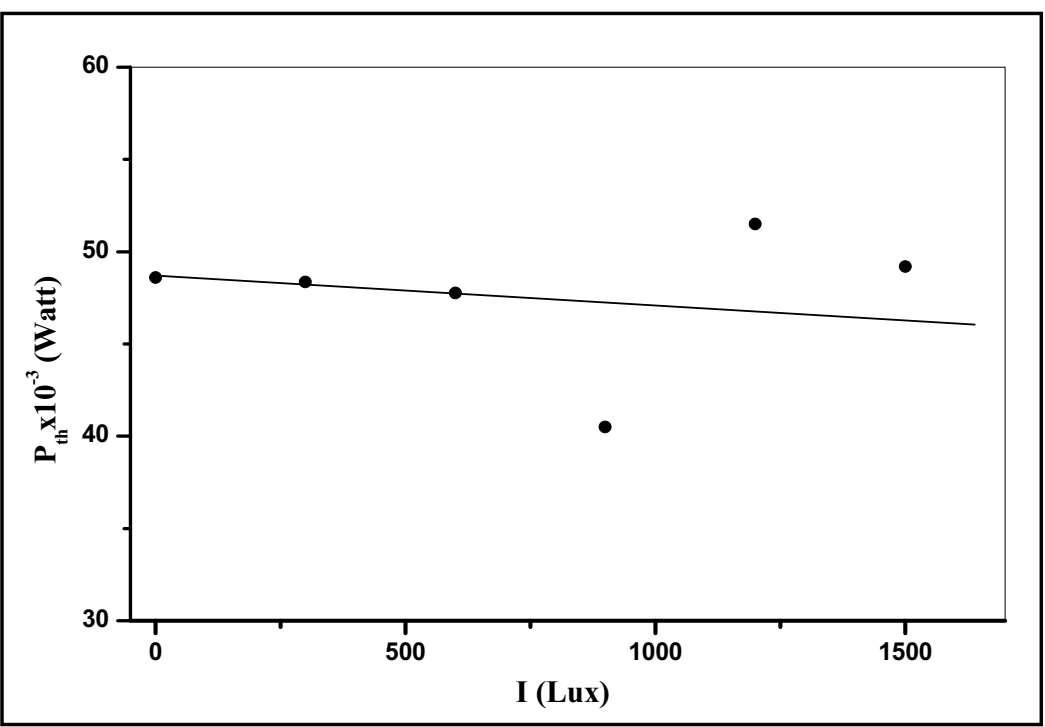

Fig. 8. The effect of light intensity on threshold power for $\mathrm{TIInS}_{2}$ single crystal.

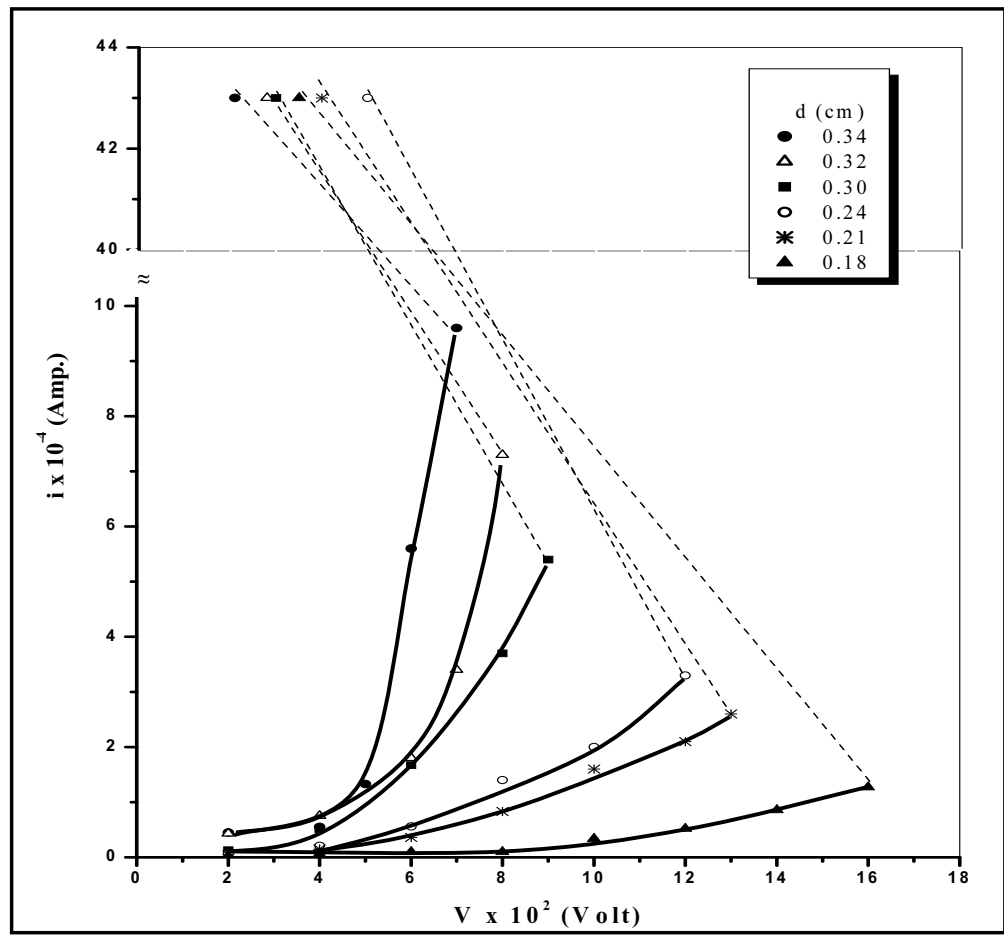

Fig. 9. The effect of TIInS $S_{2}$ sample thickness on the VAC. 


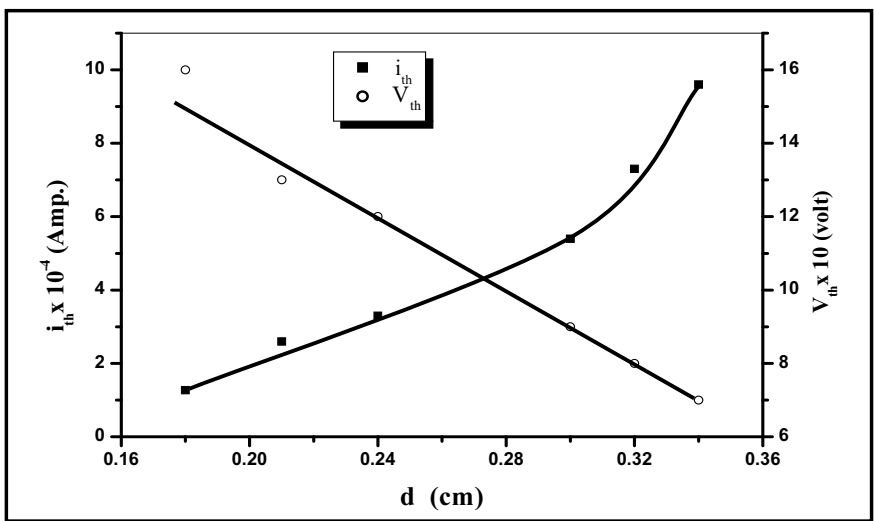

Fig. 10. Variation of threshold current and voltage with $\mathrm{TIInS}_{2}$ sample thickness.

One can say that an increase of the specimen thickness lowers the potential for the switching process in a specimen. The variation of the threshold power $\left(\mathrm{P}_{\text {th }}\right)$ with sample thickness plotted in Fig. 11. It is seen that the threshold power increases linearly with increasing thickness, i.e. the power required for switching decreases as the thickness of the sample decreases. The dependence of the threshold field $\left(\mathrm{E}_{\mathrm{th}}\right)$ on the thickness of the active region is plotted in Fig. 12. As shown, the threshold field decreases with increasing specimen thickness, this supports the suggestion that the mechanism of the switching in $\mathrm{TlInS}_{2}$ sample may involve both electronic and thermal processes ${ }^{[23]}$. The ratio between $\mathrm{R}_{\mathrm{OFF}}$ and $\mathrm{R}_{\mathrm{ON}}$ state resistivities decreases with thickness and reach a very low value at higher thickness. The resistance ratio varies from 14.9 to 154.8 in the range of sample thickness under test.

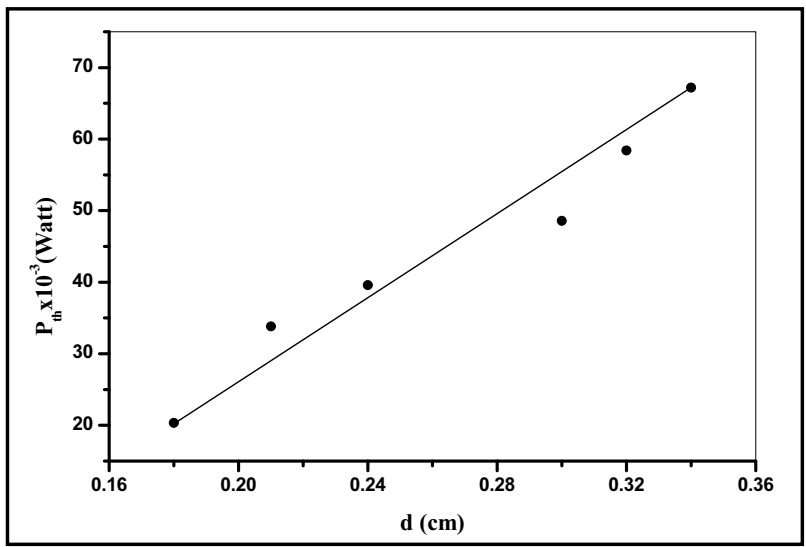

Fig. 11. The effect of the thickness of active region on threshold power for $\mathrm{TIInS}_{2}$ single crystal. 


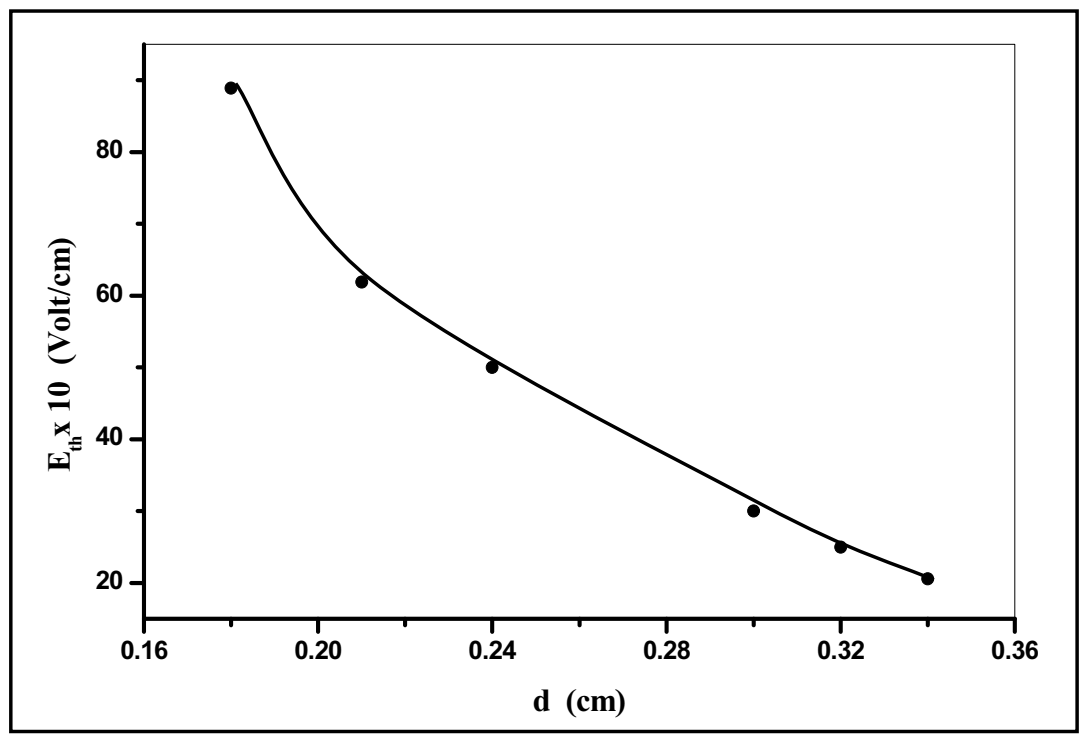

Fig. 12. Effect of sample thickness on threshold field in $\mathrm{TIInS}_{2}$ single crystal.

\section{References}

[1] Qasrawi, A. F. and Gasanly, N. M., Cryst. Res. Tech. 39: 439 (2004).

[2] Gasanly, N. M, Aydindi, A., Bek, A. and Yilmaz, I., Sol. Stat. Commun., 105: 21 (1998).

[3] Allakhverdiev, K. R., Sol. Stat. Commun., 111: 235 (1999).

[4] Hanias, M. P., Anagnostopoulous, A. N., Kambas, K. and Spyridilis, J., Mat. Res. Bull., 27: 25 (1992).

[5] Isaacs, T. J. and Feichtner, J. D., J. Sol. Stat. Chem., 14: 260 (1975).

[6] Mikailov, F. A., Kazan, S., Rameev, B. Z., Acikgoz, M. and Akta, B., Phys. Stat. Sol. A, 203: 1580 (2006).

[7] Allakhverdiev, K., Hanna, S., Gulubayov, A.K., Özbek S., Gunay, E. and Huseinova, D., International J. Infrared and Millimeter waves, 26: 1741 (2005).

[8] Qasrawi, A. F. and Gasanly, N. M., J. Mat. Sci., 41: 3569 (2006).

[9] ÖZdemir, S., Süleymanov, R. A., Allakhverdiev, K. R., Mikailov, F. A. and Civan, E., Sol. Stat. Commun., 96: 821 (1995).

[10] Deiseroth and Walther, Z. Anorg. Chem., 622: 611 (1996).

[11] Hussein, S. A. and Nagat, A. T., Cryst. Res. Technol., 24: 283 (1989).

[12] Hussein, S. A., Cryst. Res. Technol., 24: 467 (1989).

[13] Ovshinsky, S. R. and Flutzsche, H., IEEE Trans. Electron Devices, 20: 91 (1973).

[14] Saleav, E. Y., Tagiev, B. G., Rzaev, M. A., Nani, R. K., Abdullaeva, S. G., Mamedov, G. M., Askerov, I. M. and Pliev, F. I., Phys. Stat. Sol. A, 16: 143 (1973). 
[15] Aliev, S. I., Niftiev, G. M., Pliev, F. I. and Tagiev, B. G., Sov. Phys. Semicond., 13: 340 (1979).

[16] Nagat, A. T., Hussein, S. A., Gameel, Y. H. and Gamal, G. A., Phys. Stat. Sol. A, 121: 201 (1990).

[17] Nassary, M. M., Hussein, S. A. and Nagat, A. T., Cryst. Res. Technol., 29: 869 (1994).

[18] Al-Ghamdi, A. A., Hussein, S. A. and Nassary, M. M., Material Sci. Res. India, 2: 107 (2004).

[19] Boer, K. W. and Ovhinsky, S. R., J. appl. Phys., 41: 2675 (1970).

[20] Vezzoli, G. C., Walsh, P. J. and Doremus, L. W., J. non-crystall. Sol. 18: 333 (1975).

[21] Hirashima, H., Watanabe, Y. and Yashinda, T. Y., J. noncrystall. Sol., 95, 96: 825 (1987).

[22] Kolomiets, V. G., Lebedev, E. A. and Taksami, I. A., Sov. Phys. Semicond., 3: 267 (1969).

[23] S. Prakash, S. Asokan and D. B. Ghare, J. Phys. D: Appl. Phys., 29: 2004 (1996). 


\section{سلوك ظاهرة القطع و التوصيل في شبه الموصل الثنلاثي الثنالكو جينيدي ثاليوم-إنديوم-ثنائي الكبريت}

نجات توفيق عباس، و فاطمة باهبري، و مصطفى محمد مبارك، و حمدي

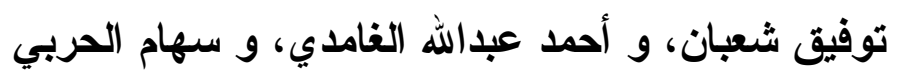
قسم الفيزياء - كلية التربية للبنات - جامعة الدلك عبدالعزبيز

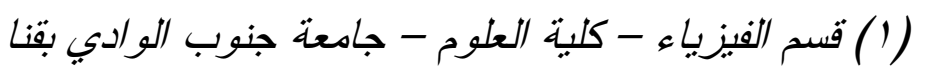

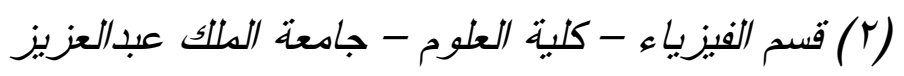

الدستخلص. لقد جذبت دراسة الخو اص الفيزيائية لأثباه الموصلات

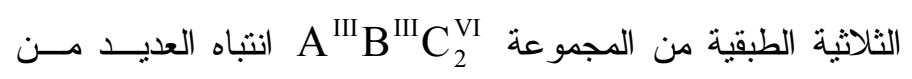

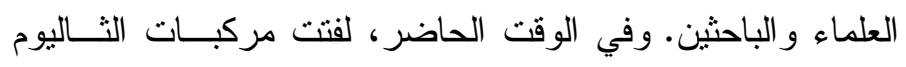

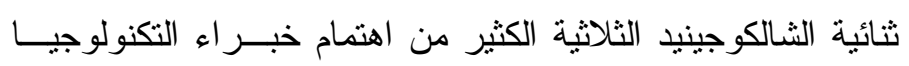

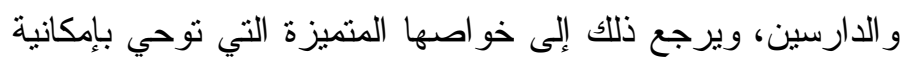

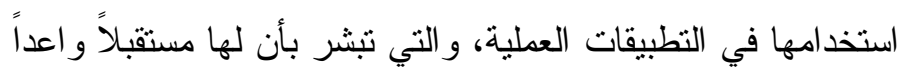

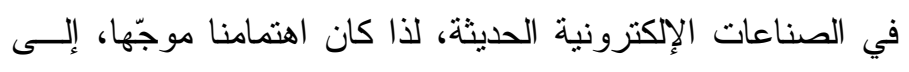

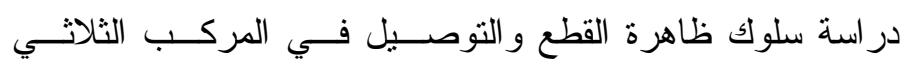

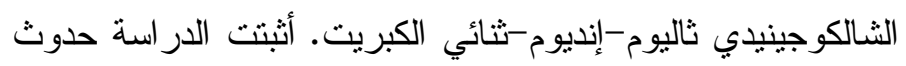

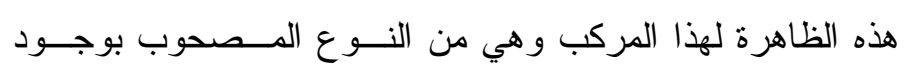

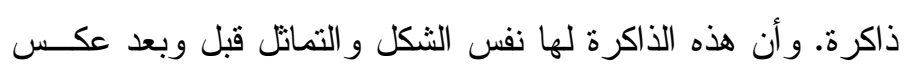

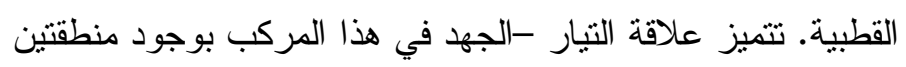

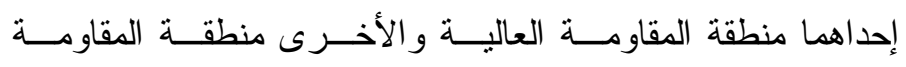

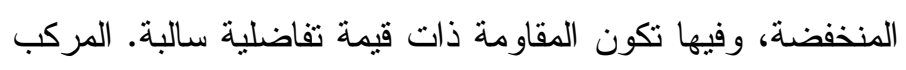
ثاليوم-إنديوم-ثنائي الكبريت تظهر فيه خاصية القطع و النوصـيل 
ذات الهيئة المميزة من النوع S-shape. درست العو امل الهـؤثرة

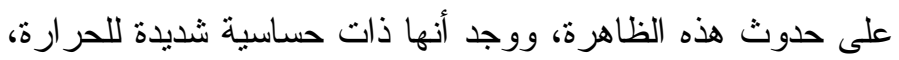
وشدة الاستضاءة. كما أن سمك العينة يؤثر على حدوثها. تم تحديد

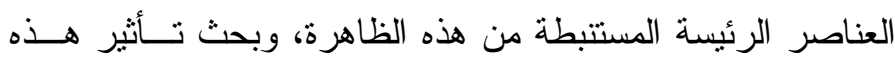
العناصر بالظروف الدحيطة بالعينة. هذه الدراسة تعتبر الأولى على الثى

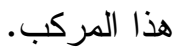

